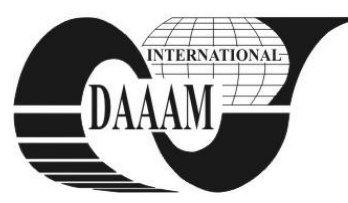

Annals of DAAAM for 2011 \& Proceedings of the 22nd International DAAAM Symposium, Volume 22, No. 1, ISSN 1726-9679 ISBN 978-3-901509-83-4, Editor B. Katalinic, Published by DAAAM International, Vienna, Austria, EU, 2011 Make Harmony between Technology and Nature, and Your Mind will Fly Free as a Bird

\title{
THE INFLUENCE OF THE NUMBER OF TEFLON-COATED LAYERS OVER THE VIBRATIONS AND NOISES TO GEAR UNITS WITH WHEEL CYLINDRICAL GEARS
}

\author{
CARAMIDARU, V[irgil] D[an]; VELA, I[on]; TUFOI, M[arius] \& GRUESCU, C[onstantin] A[ndrei]
}

\begin{abstract}
This article represents a summary of the documentation and of theoretical and experimental research activity carried out by the authors in the field of the vibrations and noises produced by the transmission with Teflon-coated cylindrical gears. The experimental researches were performed on a test stand existing within the University "Eftimie Murgu", Resita, on whose gear a one, two and three layers of fluoropolymerised Xylan 1052 were filled.

The purpose of the study is to analyse the influence of the number of the Teflon coated layers on the vibrations and noises.
\end{abstract}

Key words: vibration, noise, fluoro-polymerised, Xylan 1052, torque loadings

\section{INTRODUCTION}

These coating technologies give to the metal surface superior tribological properties under poor lubrication, or dry friction, by applying fluoro-polymer composite materials. Another advantage of these technologies is that they can be applied on metal support new or if worn, within the fluoropolymer layer thickness can be achieved, there are also reconditioning technology, saving the metal support, which means an important economy of material and workmanship. These technologies are environmental technologies.

Fluoro-polymer material used to improve the tribological behavior of the gear teeth and for the noise reduction is the Xylan 1052 dispersion - produced by Whitford Plastics Ltd, the UK, which is applied only on the flanks of teeth gears in one, two and three layers, the thickness of a layer being, after appropriate heat treatment, of 12 to 20 microns. The fluorpolymer layer obtained after appropriate heat treatment resists to a range of operating temperatures between $195 \div 285^{\circ} \mathrm{C}$ and can operate at extreme pressure, which can exceed those of $3500 \mathrm{kgf} / \mathrm{cm} 2$.

\section{PROBLEM FORMULATION}

The reducer is a horizontal-stage, with a step and coaxial input and output shaft.

For testing at variable speeds, the driving was done from a DC motor and as loading system, which makes possible the variation of torque transmitted by gear, was chosen the involvement of oil pumps with a geometrical volume of 405 $\mathrm{cm}^{3} /$ rot which can provide a maximum pressure of 25 bar. The check of the power transmitted, respectively of the torque, to the input shaft and output shaft of the gearbox, was using T-10 FS torsiometrical flanges.

For isolation gear in terms of possible vibration from the driving car (electric motor) and driven machine (pump), were chosen couplings with rubber bands on the input shaft, respectively with rubber bands on the output shaft.These couplings have the advantage of allowing quick disconnection and requires no alignment, respectively rigorous centering. The measuring of the vibration and noise were made through PULSE platform 11, existing in the equipment of Eftimie Murgu University from Resita, with related software (FFT analyzer (Fast Fourier Transformation) type 7700) capable of receiving signals from sensors on four channels, produced by The Brüell \& Kjaer.

The first three channels were used to type piezoelectric accelerometers 4524 B (triaxial accelerometers with three independent outputs for measurements along three orthogonal directions) and the fourth channel was used for piezo frequently microphone with frequency between $8 \mathrm{~Hz}$ and $16 \mathrm{kHz}$ especially designed for accurate and reliable measurements of the sounds. In Figure 1 transducers of vibration and noise are placed.

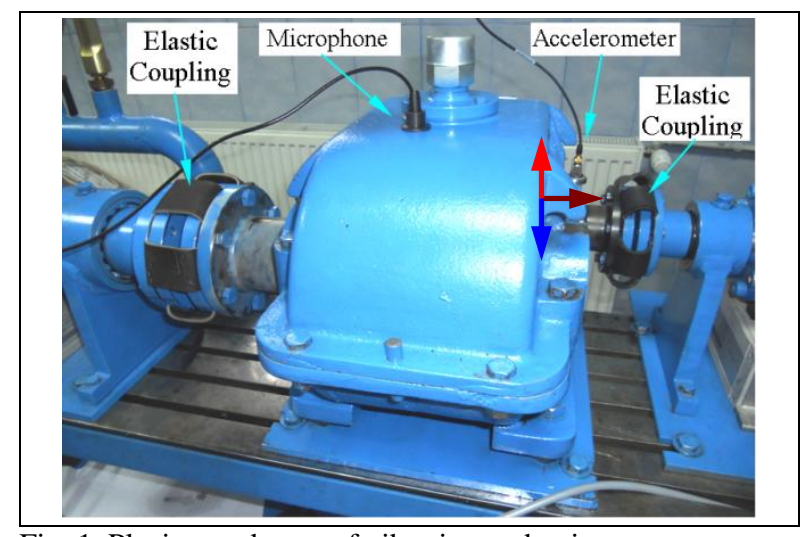

Fig. 1. Placing traducers of vibration and noise

\section{EXPERIMENTAL TESTS}

Experimental tests were made on a pair of gears (pinion + gear wheel), the angle of the teeth $11^{\circ}$ and with teeth processed by milling and on which (teeth), one, two and three layers of Fluor-polymer Xylan 1052 were made in collaboration with Technicoat ROMANIA SRL Campina. Data collection was made at the same six-speed motor drive: $\mathrm{n}_{1}=1.000,1.100$, $1.200,1.300,1.400$ and $1.500 \quad[\mathrm{rpm}]$. No vibration measurements were made at engine speeds below 1.000 [rpm], because dynamic effects become apparent at increasing speed at low revs not being able to draw relevant conclusions, respectively, for pump gear, used as a brake not work optimally in the speeds under $390 \mathrm{r} / \min \left(\mathrm{n}_{2}=\mathrm{n}_{1} / \mathrm{i}=1000 / 2.59=395.3\right.$ $[\mathrm{r} / \mathrm{min}])$. At each speed in part, vibration measurements were made at the same eight steps of torque loadings: $\mathrm{Mt}=16,19$, $22,26,29.5,32.5,35.5,38.5[\mathrm{Nm}]$. Extreme values were resulted from the specific conditions of the made test stand. Figure 2 shows the mounting position of the pinion and gear wheel. Teeth are covered with Xylan 1052 dispersion of dark green colour as shown in Figure 2. 


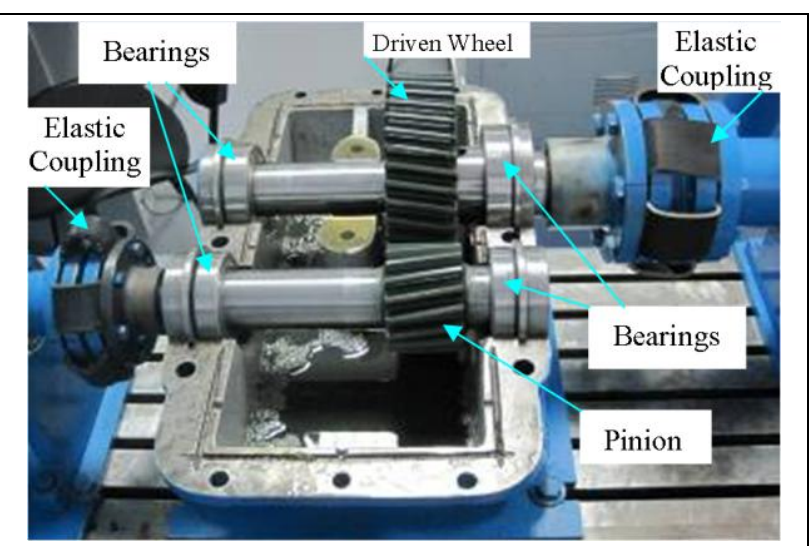

Fig. 2. The mounting position of the pinion and gear wheel

\section{EXPERIMENTAL RESEARCH}

Because we wanted to study only the vibration produced by gears, the analyze FFT (Fast Fourier Transformation) was used, recording peaks (amplitudes) of the accelerations and velocities measured at the frequency of engagement, respectively its harmonics. The values of these frequencies are shown in Table 1.

\begin{tabular}{|l|c|c|c|c|c|c|}
\hline $\begin{array}{l}\text { Rotation } \\
\text { speed } \\
{[\text { [rpm }]}\end{array}$ & 1000 & 1100 & 1200 & 1300 & 1400 & 1500 \\
\hline $\mathrm{f}[\mathrm{Hz}]$ & 283.33 & 311.67 & 340.00 & 368.33 & 396.67 & 425.00 \\
\hline $2 \times f[\mathrm{~Hz}]$ & 566.67 & 623.33 & 680.00 & 736.67 & 793.33 & 850.00 \\
\hline $3 \times \mathrm{xf}[\mathrm{Hz}]$ & 850.00 & 935.00 & 1020.00 & 1105.00 & 1190.00 & 1275.00 \\
\hline
\end{tabular}

Tab. 1. Frequency of engagement

In the graph in Figure 3 there are presented in comparison: the teflon-coated teeth with one, two or three layers of fluoropolymer material Xylan 1052, the maximum amplitude variation of acceleration on two axex $(\mathrm{X}$ and $\mathrm{Y})$ of the bearing $\mathrm{A}$, measured at maximum speed $(\mathrm{n}=1.500 \mathrm{rpm})$ of the driven motor, depending on torque loadings.

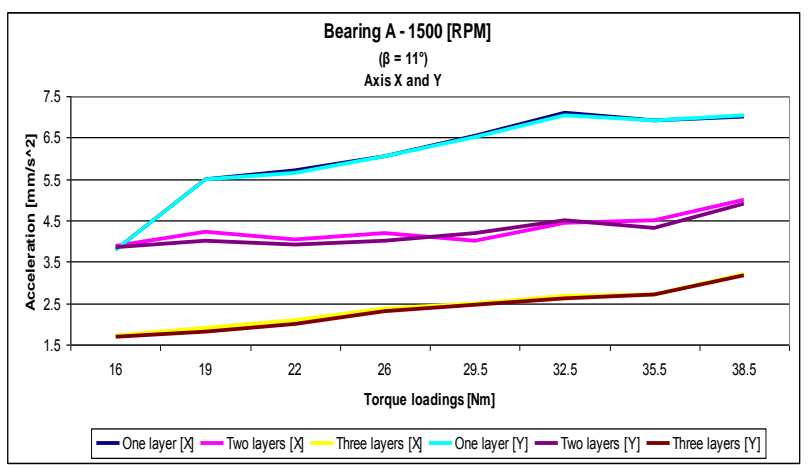

Fig. 3. Variation of acceleration

Acording to the graph in Figure 3 from the teeth covered with one layer of Xylan 1052 there is registred a decrease of:

- $30 \%$ for the teeth covered with two layers Xylan 1052 ;

- $60.98 \%$ for the teeth covered with three layers Xylan 1052 ;

In the graph in Figure 4 there are presented in comparison: the teflon-coated teeth with one, two or three layers of fluoropolymer material Xylan 1052, the changes in noise levels measured at maximum speed $(\mathrm{n}=1.500 \mathrm{rpm})$ of the driven motor, depending on torque loadings.

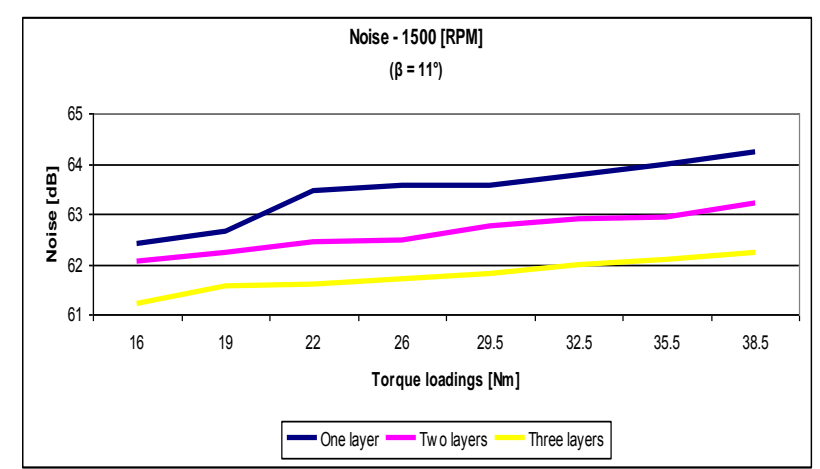

Fig. 4. The change in noise levels measured

Acording to the graph in Figure 4 from the teeth covered with one layer of Xylan 1052 there is registred a decrease of:

- $1.31 \%$ for the teeth covered with two layers Xylan 1052 ;

- $2.65 \%$ for the teeth covered with three layers Xylan 1052 ;

\section{CONCLUSIONS}

Appying a multi-layer film dispersion type Xylan 1052, on the sidewall surfaces of teeth, there were obtained decreases of maximum amplitude of vibration and noise. Overall, it was observed that in most cases, there are larger differences between one and two layers than two to three coats applied. However the film with three layers is damper than a film with two layers, but the difference is not visible in all cases investigated. This leads us to conclude that if there is no need to get the best damping of vibrations and noises it is better not to do additional work and to choose a film with two layers Xylan 1052 .

\section{ACKNOWLEDGEMENTS}

Special thanks to Mr. Zoltan Korka from "Reductoare Resita SA" for the design and execution of the test stand. We also thank SC Technicoat ROMANIA SRL Campina for filling the tooth flanks of the gears with one, two and three layers of fluoropolymer Xylan 1052.

\section{REFERENCES}

Bratu, M.; Ropota, I.; Vasile, O.; Dumitrescu, O.; Munteanu, M. (2011). Reserch on the absorbing properties of same new types of composite materials, Romanian Journal of Materials, vol. 41 (2), ISSN 1583-3186, pp. 147-154

Korka, Z. I. (2009). Cercetari privind reducerea vibratiilor in functionarea reductoarelor $\mathrm{cu}$ roti dintate cilindrice, Teza de Doctorat, Universitatea "Eftimie Murgu" Resita, Facultatea de Inginerie

Korka, Z.; Vela, I. (2008). Design and Execution of a Test Rig for Studying the Vibrations of a Gearbox, Analele Universitatii “ Eftimie Murgu” Resita, Fascicola Inginerie, ISSN 1453-7397, Nr.1, pp. 134-140

Agemi, M. F.; Ognjanovic, M. (2004). Gear Vibration in Supercritical Mesh-Frequency Range, FME Transactions, vol. 32, nr. 2, pp. 87-94

Nguyen, V. K.; Thai, M. C.; Nguyen, P. D. (2004). Modelling Parametric Vibration of Gear-Pair Systems as a Tool for Aiding Gear Fault Diagnosis, Technische Mechanik, Band 24, Heft 3-4, pp. 198-205 